\title{
EM BUSCA DE OUTRA RACIONALIDADE
}

SEEKING ANOTHER RATIONALITY

EN BUSCA DE OTRA RACIONALIDAD

FELÍCIO, Munir Jorge ${ }^{1}$

ROSA, Paulo Roberto2

\begin{abstract}
RESUMO
Lutar para emancipar o território constitui um enfrentamento contínuo e processual a partir do qual, novos saberes e novas identidades são construídas, modificadas e substituídas visando sobrepor os saberes e identidades impostas de cima para baixo para manter o funcionamento da ordem existente e consolidar a racionalidade econômica. $O$ objetivo principal deste artigo consiste em buscar alternativas a essa racionalidade sabendo de sua hegemonia e abrangência. Para construir outra racionalidade as alternativas emancipadoras do Sul Global apontarão possibilidade de se viver e produzir a vida de outra maneira ao enfrentar as novas formas de dominação.
\end{abstract}

Palavras-chave: Alternativas emancipadoras. Outra racionalidade. Participação. Acumulação capitalista.

\section{ABSTRACT}

Fighting to emancipate the territory constitutes a continuous and procedural confrontation where new knowledge and new identities are constructed, modified, and replaced aiming to expose the knowledge and identities imposed from above to maintain the functioning of the existing order and consolidate economic rationality. The main objective of this text is to seek alternatives to this rationality, knowing of its hegemony and comprehensiveness. To construct another rationality, the emancipatory alternatives of the Global South will point out the possibility of living and producing life in another way to face the new forms of domination.

Keywords: Emancipatory alternatives. Other rationality. Participation. Capitalist accumulation.

\section{RESUMEN}

Luchar para emancipar el territorio constituye un enfrentamiento continuo y procesual a partir del cual, nuevos saberes y nuevas identidades son construidas, modificadas y reemplazadas visando sobre poner los saberes e identidades impuestas de encima para abajo para mantener el funcionamiento del orden existente y consolidar la racionalidad económica. El objetivo principal de este artículo consiste en buscar alternativas a esa racionalidad sabiendo de su hegemonía y alcance. Para construir otra racionalidad las alternativas emancipadoras del Sur Global apuntarán a la posibilidad de vivir y producir la vida de otra manera al enfrentar las nuevas formas de dominación.

Palabras clave: Alternativas emancipatorias. Otras racionalidades. Participación. Acumulación capitalista.

${ }^{1}$ Cátedra UNESCO de Educação no Campo e Desenvolvimento Territorial-Unesp - Presidente Prudente - São Paulo - Brasil.

${ }^{2}$ Instituto Federal de Educação, Ciência e Tecnologia de São Paulo - IFSP - Presidente Epitácio - São Paulo -Brasil. 


\section{INTRODUÇÃO}

$\mathrm{Na}$ tentativa de apreensão cognoscitiva do real a racionalidade econômica, de tendência hegemônica, tem como ponto de partida o "pressuposto de que a comunidade científica sabe como é o mundo" (KHUN, 2009, p. 24). Esse pressuposto funciona como uma armadilha para os pesquisadores, pois "o espírito científico é incapaz de se pensar de tanto crer que o conhecimento científico é o reflexo do real" (MORIN, 2010, p. 21). A racionalidade econômica se mantém ao engendrar conceitos perversos como o de globalização, por exemplo.

Refletir e buscar alternativas a essa racionalidade consiste no objetivo principal do presente texto, que reuniu na primeira parte as análises de Zibechi (2006) que trata da rebeldia e da autonomia de novos sujeitos que se organizam nos territórios; e Braga (2017) por analisar as lutas para assegurar o respeito aos direitos sociais.A segunda parte discutirá o intervencionismo do Estado como imprescindível à acumulação capitalista a partir das análises de Hayek (1977),Dardot e Laval (2016) e Jardim (2009). O diálogo entre as duas partes se estabelecerá ao verificar as consequências e as características da intervenção estatal, bem como as transformações sociais que a acompanham diante das diversas iniciativas e mobilizações presente nos territórios em busca de emancipação.

\section{PARA CONSTRUIR OUTRA RACIONALIDADE: AS ALTERNATIVAS EMANCIPADORAS DO SUL GLOBAL}

A inovação das lutas sociais e a reorganização de novos sujeitos sociopolíticos em redes de mobilizações nos territórios em resistência criam, desde as últimas três décadas, as condições necessárias para despertar as forças da emancipação visando suplantar a ordem existente como detalham as análises de Zibechi (2006). A rebeldia e a autonomia dos novos sujeitos mobilizados nos territórios almejam construir emancipação desde baixo, desde os porões da sociedade neoliberal, por conceber a participação como conquista, como luta, como processo infindo.

A participação, o envolvimento e o conflito estão presentes nas análises de Zibechi (2006) no contexto latino-americano por tratar dos sujeitos em movimentos que, a partir dos seus territórios, lutam por outro mundo, diferente, gerador de tensão emancipadora e que enfrentam as novas formas de dominação presente no bojo dos programas sociais e das políticas públicas como articulação do controle social.

\footnotetext{
Un mundo nuevo está nasciendo en los territorios de los movimientos. Un mundo nuevo - o sea, diferente - se abre pasoenlasgrietasdel sistema, que los habitantes delsubsuelovienenhoradando desde hacealgunas décadas [...].Estosotros mundos son también diferentes entre sí, pero tienen en común la lucha por la dignidad, la autonomía, la tensión emancipatoria que constituyen la argamasa con la que nace y crece nuestro otro mundo (ZIBECHI, 2006, p. 123-124).
}

Lutar para emancipar o território constitui um enfrentamento contínuo e processual a partir do qual novos saberes e novas identidades são construídas, modificadas e substituídas visando sobrepor os saberes e identidades impostas de cima para baixo para manter o funcionamento da ordem 
existente. Os novos sujeitos sociopolíticos geram com autonomia e protagonismo outra forma de poder por acreditarem que é pela participação e pela luta contra o poder estabelecido na ordem existente.

Buscam alternativas ao desenvolvimento proposto pelo projeto neoliberal caracterizado pela concentração de terra, renda e oportunidades. São os negros e as nações indígenas que resistem à colonização secular em toda América Latina; camponeses sem terra no Brasil e organizados pela Via Campesina em todo globo; os piqueteiros argentinos, os cocaleiros na Bolívia e no Peru. Os zapatistas no México, os estudantes que ocuparam, recentemente, as universidades no Brasil com a luta pela melhoria na qualidade de ensino, como as que foram analisadas por Zibechi (2006). Ele ressaltou a importância da estratégia territorial que se desdobra de dentro para fora esvaindo pelas brechas da dominação capitalista para ocupar as lacunas e expandir "mundos diferentes; diferentes del mundo hegemônico que hemos dado enllamar capitalismo-imperialismo-mundialización" (ZIBECHI, 2006, p. 123). São formas organizativas diversas e heterogêneas desenvolvidas a partir da defesa do território onde se encontra o enorme contingente populacional.

As alternativas ao sistema capitalista são gestadas nos territórios pela produção de vínculos para atender o ritmo próprio de cada povo e de cada comunidade pelas atitudes "diferentes hacialos estados nacionales, formas diversas de construir susorganizaciones, dispares modos de afrontar las relaciones conelterritorio y particularidades encuanto a las formas de abordar laeducación, los cuidados de lasalud y laproducción" (ZIBECHI, 2006, p. 124).

Das iniciativas dos movimentos populares, indígenas e camponeses as práticas educativas formais e informais almejam a construção do sujeito com e dentro do processo de ocupação do território transformando a escola num espaço de enfrentamento. Trata-se do confronto entre duas estratégias: a dos movimentos e a do Estado. "Si la lucha social no consigue modificar los lugares que ocupábamos antes, estará destinada al fracaso, ya que reproduce los roles opresivos que hicieron nacer ese movimiento" (ZIBECHI, 2006, p. 127).

O movimento se constitui em sujeito educativo e não o Estado para desenvolver, em quem aprende, a consciência crítica e ampliar a reflexão sobre a ordem existente ao adquirir uma visão de mundo distinta daquela que é própria do discurso oficial do Estado imiscuído no processo educativo. Desta transformação revolucionária, como intencionalidade pedagógica, emerge a urgente necessidade em desenvolver a capacidade técnica com a qual expandir a produtividade para garantir independência e autonomia de quem está na luta.

Ocupar a escola e nela desenvolver uma educação em movimento significa reproduzir o movimento que luta por uma nova ordem, por um novo mundo, pois

\footnotetext{
Una cosa es educar para el movimiento o en el movimiento; otra es hacerlo en movimiento. Aqui lo decisivo no es qué pedagogía se sigue ni qué modelo de escuela se persigue, sino el clima y las relaciones humanas vinculadas a las prácticas sociales. La educación no es más - ni menosque un clima social inserto en relaciones sociales; el resultado del proceso educativo dependerá del tipo de clima y del carácter de las relaciones sociales en un espacio-tiempo determinado (ZIBECHI, 2006, p. 126, grifosdo autor).
}

O vínculo da tarefa educativa com o movimento, que lhe dá origem, está na mesma incerteza, tanto da escola quanto da luta, por ambas se fazerem e decidirem suas trajetórias. Assim, a prática 
pedagógica necessita de tempos diferentes para fazer avançar a aprendizagem coletiva. "Convertir al movimiento en sujeto pedagógico implica poner en un lugar destacado la reflexión y la evaluación permanentes de todo lo que está sucediendo, abrirse como espacios de auto-reflexión [...]", como ressaltou Zibechi (2006, p. 127).

Como estratégia de sobrevivência para garantir autonomia e ampliar a independência, os movimentos rurais e urbanos, avançam aprendendo a produzir o necessário para assegurar a sobrevivência dos seus quadros. Nas escolas desenvolvem a capacidade técnica e criam tecnologia para cultivar sem o uso de agrotóxicos e dos transgênicos. Em paralelo com a nova matriz educativa empenham-se, também, em desenvolver uma nova organização produtiva para romper e superar a luta de classes. Para produzir sem capitalistas e operários faz-se necessário vencer a inércia individualista. Para isso,

\footnotetext{
Tres aspectos merecen ser destacados: el papel de la lucha en la creación de vínculos fuertes entre los obreros. Los intentos de superar la división entre productores y consumidores - y por lo tanto de eludir la lógica del mercado monopólico - y, por último, la tensión emancipatoria respecto de la división del trabajo (ZIBECHI 2006, p. 132).
}

Historicamente os movimentos rurais como os indígenas, camponeses e os que lutam por terra aprenderam a produzir o necessário para garantir a sobrevivência, lógica que, paulatinamente, tem se desenvolvida também nos movimentos urbanos, como os sem teto, os piqueteiros, os operários das fábricas recuperadas, entre outros. Criam inúmeros coletivos para recuperar as sementes crioulas, de verduras e hortaliças; oficinas de costura e bordado; grupos de mães nas periferias das metrópoles aprendem a fazer velas e artesanatos; doces em conserva e juntam recursos para construir a própria padaria.

Produzir sem patrões e empregados significa romper a essência própria do capitalismo demonstrando a possibilidade de se viver e produzir a vida de outra maneira. Eis a busca atual de alternativas ao desenvolvimento, pois sem o instituto "sagrado" da propriedade privada e com outra divisão social que se sobreponha a luta de classes é possível superar a divisão entre produtores e consumidores, entre capitalista e operário. Com autonomia criam o que denominam de comércio justo, consumo solidário e consciente e "recuperanel carácter original del mercado: transparencia, benefícios exíguos, competencia controlada, liberación, y ser el terreno de lagente común" (ZIBECHI, 2006, p. 133, grifos do autor).

Fazem parte do mercado, mas não obedecem à sua lógica e nem alimentam sua expansão em direção à infinita acumulação capitalista. Apoderaram-se do processo produtivo no campo e na cidade desfazendo seu dinamismo "aldes-fetichizar o des-cosificarlas relaciones enel seno deltaller: las que aparecían como relaciones entre cosas, reaparecen como relaciones sociales, entre personas" (ZIBECHI, 2006, p. 137). E, esse relacionamento entre seres humanos, como forma de vida, se constitui na gênese coletiva promotora de saúde.

O poder regenerativo da saúde pessoal encontra-se disponível e acessível na comunidade pelos seus poderes curativos "expropiados por el saber médico y el Estado. Pero implica, además, liberarse del control que el capital ejerce sobre la salud a través de las multinacionales farmacéuticas, 
que jugaron un papel destacado en el proceso de medicalización de la sociedad' (ZIBECHI, 2006, p. 138, grifosdo autor). Recuperar os saberes ancestrais consiste em reaprender a sabedoria das comunidades quando enfrentavam ambientes hostis promotores de medo.Àscontribuições de Zibechi (2006) somam-se as de Braga (2017) ao demonstrar que a luta pela defesa do território consiste numa frente de enfrentamento à expansão capitalista, da qual também faz parte a luta do precariado por uma cidadania ativa.

A rebeldia é a forma de viver implementada quando o precariado, nas últimas quatro décadas, se insurge contra a acumulação por espoliação do neoliberalismo na qual prevalece a logica do salvese quem puder ou quem pode mais, chora menos. Braga (2017, p. 21) ressalta que "a distribuição desigual dos impactos da crise (global desde 2008) nas diferentes sociedades nacionais não apenas radicalizou as disparidades econômicas entre os países do Norte e do Sul como tem alimentado soluções regressivas por toda parte".

As análises de Braga (2017) trataram do neoliberalismo no Sul Global e o processo de implementaçãoda precarização gerando as lutas sociais, as quais foram estudadas por ele comparando-as entre aquelas que emergiram em Portugal de meados de 2000 a 2013; àquelas desenvolvidas na África do Sul e no Brasil. Precarizar o mundo do trabalho foi necessário, mas não suficiente, para atender as demandas do Norte Global, por isso ressaltou Braga que

\footnotetext{
A crise da globalização em 2008 foi um divisor de águas na política internacional, levando as classes dominantes do Norte Global a recorrer ao intervencionismo estatal a fim de tentar estabilizar o sistema. No entanto, uma vez assegurado tal objetivo, voltaram à ofensiva sobre as classes subalternas com uma versão ainda mais crua do neoliberalismo. Os trabalhadores estão pagando a conta da crise por meio de rigorosos planos de austeridade e de padrões de vida cada dia mais baixos. Em poucas palavras, a onda de espoliação neoliberal tende a semear revoltas e multiplicar conflitos de difícil solução nos marcos democráticos tradicionais (BRAGA, 2017, p. 2223)
}

A expansão da corrente neoliberal desde a crise de 2008 prima por restringir a democracia em vez de reduzir desigualdades. As políticas neoliberais se impõem de forma totalmente contraria aos anseios da população, por privilegiar enormes benefícios aos muitos ricos. As instituições financeiras e corporações multinacionais guiam se pela lógica perversa do "tudo para nós e nada para os outros" e controlam todo o sistema social e politico concentrando o poder nas mãos dos ricos e dividindo a população como artimanha para evitar que sua união possa ameaçar o desenrolar da ordem existente.

A crise do fordismo da década de 1970 e a consolidação da hegemonia neoliberal impulsionada na década de 1980 inauguraram a expansão da mercantilização subvertendo as formas sociais de regulação do mercado previstas por Polanyi (2000). O resultado dessas alterações incrementou a insegurança econômica e majorou a desigualdade a nível global chamando a atenção de Braga (2017) a fazer análises cujo

[...] objetivo principal será enfocar a precariedade dos modos de vida e de trabalho dos subalternos, a fim de revelar uma das principais características da crise atual, isto é, a relação entre o avanço do neoliberalismo e a renovação das lutas sociais, particularmente em Portugal, na África do Sul e no Brasil (BRAGA, 2017, p. 25). 
O precariado português se constitui, no final dos anos 1980, uma das principais forças sociais do trabalho a se rebelar contra as incertezas e desigualdades advindas da mercantilização do trabalho. Dentre as principais determinações relacionadas às transformações da estrutura de classe em Portugal a "formação do precariado pós-fordista português e à sua transformação em um decisivo sujeito da ação coletiva no contexto europeu" (BRAGA, 2017, p.42, grifos do autor) concentra dinamismo de rebeldia com força política.

O precariado do período pós-2008 se efetivou nas organizações autônomas de jovens precarizados com agenda própria e temáticas renovadas de lutas sociais. Nem a estrutura sindical e nem os partidos políticos conseguiram corresponder ao momento de luta da classe trabalhadora portuguesa. O precariado português se levantou com renovado protagonismo político. Inicia-se um ciclo histórico de resistência à mercantilização do trabalho em Portugal "a partir da indagação a respeito de qual a importância do jovem precariado português no ensaio de formação de um contramovimento aos avanços do neoliberalismo no Sul da Europa" (BRAGA, 2017, p.42).

Os ataques austericidas à cidadania salarial ocorridos em Portugal se efetivaram também na semiperiferia capitalista de outras regiões como o que aconteceu na África do Sul. Nela a crise da globalização dissipou parte dos direitos trabalhistas e do sistema de proteção africano. "Evidentemente, a exemplo do que ocorreu durante o domínio do regime de apartheidracial na África do Sul, esse apartheidsocial que se espalha pela semiperiferia capitalista, impulsionado pela acumulação por espoliação tem estimulado a resistência popular" (BRAGA, 2017, p.67-68, grifos do autor).

O revés recaiu novamente sobre as costas das famílias africanas excluídas quando as decisões políticas na África do Sul do novo regime avançaram em direção oposta ao discurso oficial, tendo como avaliador do alinhamento do Estado às artimanhas da globalização nada menos do que Nelson Mandela. Foi exatamente ele "que usou seu enorme prestígio político junto à população africana para legitimar a conversão do ANC ao neoliberalismo" (BRAGA, 2017, p.84). De fato, os benefícios conseguidos nas intensas lutas contra o regime apartheid foram perdidos com a vivência democrática.

O precariado avançou por diferentes frentes de mobilização como, por exemplo, as greves que foram decretadas a partir de março de 2000 e, no interior dela e, como parte dela, cresceu a solidariedade que impediu as empresas encontrarem substitutos para os grevistas. Diante da repressão policial aos grevistas houve nas periferias urbanas uma forte reação da comunidade em apoio ao movimento grevista. Os operários se posicionaram contra os "interesses da direção do ANC e ao seu projeto de criar uma burguesia negra capaz de apoiar a libertação nacional por meio da participação nos fundos de pensão controlados pelos sindicatos" (BRAGA, 2017, p.86)

A harmonização entre a mercantilização do trabalho, das terras, do dinheiro, dos serviços públicos e da estratégica participação do Estado engendrou tanto o precariado português, quanto o africano e, será também a responsável, pelo levante do proletariado precarizado, principalmente, entre as mulheres e os mais jovens no Brasil. "[...] O lulismo acabou fracassando por não ter sido capaz de, no aprofundamento da crise da globalização, permanecer reproduzindo a pacificação social que o caracterizou ao longo de mais de uma década" (BRAGA, 2017, p.121). 
A gestão petista não só não se afastou das políticas neoliberais como auxiliou na consolidação do modelo de desenvolvimento pós-fordista, periférico e financeirizado que se expandiu no Brasil entre 2003- 2014. As análises de Braga tentaram "identificar a evolução de partedas tensões sociais que se acumularam ao longo da era Lula e que, em última instância, foram responsáveis pelo enfraquecimento da capacidade de a regulação lulista continuar reproduzindo os conflitos classistas no país (BRAGA, 2017, p.96).

A hegemonia lulista conseguiu atrair a elite sindical e tentou fundi-la juntamente com os movimentos sociais ao aparelho de Estados e aos fundos de pensão. Enquanto criava as condições de efetivar a fusão ampliou as políticas publicas redistributivas tentando dissimular a luta de classes, principalmente aquela que se desenvolve com a questão salarial. Neste cenário se destaca o grupo de teleoperadores ou operadores de telemarketing, especialmente paulistanos por causa da elevada taxa de rotatividade. Eles sinalizam

[...] as contradições do modelo de desenvolvimento pós-fordista e periférico que predominou no país até recentemente. Assim, poderemos perceber que, apesar dos avanços da formalização do emprego, o atual modelo de desenvolvimento seguiu reproduzindo as condições precárias de vida e de trabalho que alimentam um estado permanente de inquietação social entre os subalternos (BRAGA, 2017, p.99-100).

Para avançar esse modelo de desenvolvimento os sindicalistas precisavam se equilibrar entre a manutenção dos canais de negociações do governo lulista e as respostas ao aumento da onda grevista advindo da base do próprio sindicalismo. O equilíbrio era necessário tanto para a cúpula do governo quanto para a base sindical. Ele se ampliou "pela absorção de sindicalistas no aparelho de Estado e nos fundos de pensão, transformando a elite sindical do país em verdadeira administradora do investimento capitalista" (BRAGA, 2017, p.105).

As políticas de espoliação impostas pela globalização financeira transformaram a elite sindical e manietou todo o aparelho que antes lutava por greves e aumento salarial e, que se encontrava a serviço de projetos alternativos de mudança social e política. $O$ avanço desse processo tem-se mostrado uma fonte de precarização da condição proletária e, de outro lado, um estímulo à aparição de contramovimentos sociais em todo Brasil. Eis a reprodução contraditória do neoliberalismo que se caracteriza pela dominação do capital financeiro monopolista. Por razões como estas, as análises de Zibechi (2006) e Braga (2017) são colaborações importantes indicando ser a periferia o lugar de onde se desenvolvem as condições necessárias e possíveis para suplantar a ordem existente.

\section{CRÍTICA À ECONOMIA POLÍTICA DA ERA DA SERVIDÃO}

Construídas com perspectivas distingas as análises de Polanyi (2000) e Arrighi (2009) almejaram compreender as nuances que deram origem da sociedade atual, especialmente no que tange a atuação do Estado e de sua interferência na vida das pessoas e na organização social como um todo. Para Polanyi (2000, p. 17) "o estado liberal foi, ele mesmo, uma criação do mercado autoregulável". A expansão do mercado e seu desenvolvimento impuseram transformações "quase" 
inexoraveis, pois o "progresso econômico, que alcançara o seu aperfeiçoamento à custa da desarticulação social" (POLANYI, 2000, p. 53). Apenas a título de exemplo verificar as implicações sociais e despovoamento advindo com a implantação dos cercamentos em terras inglesas com a expansão da Revolução Industrial.

As análises de Arrighi (2009) complementaram as compreensões de Polanyi por tentar explicar que o advento do mercado capitalista veio acompanhado do surgimento do Estado. $O$ objetivo dele consiste em analisar como se deu a relação que une a criação e a reprodução ampliada do capitalismo, como sistema mundial e os processos de formação de Estados. São como gêmeos siameses a criação de um sistema de Estados nacionais e a formação de um sistema capitalista mundial explanada por Arrighi por intermédio da sucessão dos ciclos sistêmicos de acumulação de capital, desde meados do século XV.

\footnotetext{
Serão identificados quatro ciclos sistêmicos de acumulação, cada qual caracterizado por uma unidade fundamental do agente e estrutura primários dos processos de acumulação de capital em escala mundial: um ciclo genovês, do século XV ao início do século XVII; um ciclo holandês, do fim do século XVI até decorrida a maior parte do século XVIII; um ciclo britânico, da segunda metade do século XVIII até o inicio do século XX; e um ciclo norte-americano, iniciado no fim do século XIX e que prossegue na atual fase de expansão financeira (ARRIGHI, 2009, p. 6).
}

O intervencionismo do Estado, concebido esse como imprescindível à acumulação de capital é essencial para a implantação de uma economia mundializada como a que se encontra atualmente. As três análises a seguir demonstrarão, cada qual a seu modo, as consequências e as características da intervenção do Estado, bem como as transformações sociais que a acompanharam. As análises de Hayek (1977) se posicionaram contra o intervencionismo estatizante questionando e criticando o modo hegemônico em que se encontrava o pensamento econômico ocidental, especialmente no período entre guerras. A contribuição de Dardot e Laval (2016, p. 7) procurou demonstrar que a intervenção do estado neoliberal "transformou profundamente o capitalismo, transformando profundamente as sociedades". Trata-se do que eles denominaram de grande virada proporcionada pela estratégia neoliberal.E, as contribuições de Jardim (2009) explanaram a domesticação e/ou moralização do capitalismo no governo Lula: inclusão social via mercado e via fundos de pensão, em que o "governo Lula promove a participação ativa de determinados segmentos sindicais no mercado financeiro" (JARDIM, 2009, p. 124).

As contribuições de Hayek (1977) almejavam elucidar, em 1944, quando elas vieram à tona, os problemas da futura política econômica. Na época evocava que era "o destino da Alemanha que estamos em perigo de seguir" (HAYEK, 1977, p. 4). Ele tentava compreender os acontecimentos que,durante e após a Primeira Guerra Mundial,foram responsáveis para a implantação do sistema nazista, por crer que "somos os criadores do nosso destino, em cada caso particular somos escravos das ideias que criamos" (idem).

A investida de Hayek (1977) consiste num resgate histórico dos últimos cem anos na tentativa de compreender a razão da "vitória final de um determinado conjunto de ideias, e em verificar por que motivo esta vitória acabou erguendo às primeiras posições os elementos mais pervertidos entre eles" (HAYEK, 1977, p. 8-9). Na verdade, Hayek (1977) procurava saber o que tinha produzido o sistema 
nazista. Se se buscava um sistema nacional-socialista, por quais razões terminaram aceitando um sistema totalitário? O que Hayek (1977) procurou demonstrar é que

[...] o conflito existente na Alemanha entre a "Direita" nacional-socialista e a "Esquerda" é o tipo de conflito que sempre se verifica entre facções socialistas rivais. Se esta interpretação for correta, significará, todavia, que muitos daqueles refugiados socialistas, ao aferrar-se às suas ideias, estão atualmente, embora com a melhor boa vontade do mundo, cooperando para induzir o seu país adotivo ao caminho tomado pelo Alemanha (HAYEK, 1977, p. 9-10).

Ao produzir o resgaste histórico Hayek (1977) lança a desconfiança de que a ordem existente não foi apenas resultado de forças funestas, como também, a sua existência se deve direta ou indiretamente, tácita ou explicitamente, a quem viveu nesse momento histórico:

\begin{abstract}
Estamos a aceitar quase todas as explicações para a presente crise de nossa civilização, exceto uma: que a presente situação do mundo possa ser o resultado de um verdadeiro erro de nossa parte e que a tentativa para realizar alguns de nossos mais caros ideais tenha produzido ao que parece resultados inteiramente diversos daqueles que esperávamos. Enquanto todas as nossas energias são orientadas para vencer esta guerra, é às vezes difícil lembrar que mesmo antes da guerra os valores pelos quais hoje lutamos estavam ameaçados aqui, e destruídos alhures (HAYEK, 1977, p. 12).
\end{abstract}

A realidade é sempre produto de uma evolução de ideias e, prova disso, são os sistemas totalitários instalados na Alemanha, na Itália e na Rússia, e que

[...] o conflito externo é o resultado de uma transformação do pensamento europeu a que outros foram levados de modo tão rápido que chegaram a um conflito irreconciliável com os nossos ideais, mas essa transformação não deixou de atingir-nos. [...] Tal dificuldade decorre exatamente do fato de que, para o bem delas mesmas, essas nações estavam atrasadas em relação à maioria dos povos europeus. Ainda julgamos os ideais que nos guiam, e que nos guiaram na última geração, como realizáveis somente no futuro, e não percebemos o quanto nestes últimos vinte e cinco anos, eles já transformaram não apenas o mundo mas também os nossos próprios países (HAYEK, 1977, p. 12-13).

Das transformações que sucederam a I Guerra Mundial o que chama a atenção de Hayek (1977) consiste na expansão do mundo liberal, guiado, desde o final do século XIX pelo princípio do laissez-faire. O horror totalitário que acompanharam tais transformações chocou as gerações por não saberem correlacionar os dois fatos e por permanecerem atraídos pelo socialismo. Não se atentaram que há

trinta anos HilaireBeloc, num livro que explica o que sucedeu na Alemanha melhor do que a maioria das obras escritas após os acontecimentos, diz que 'o efeito da doutrina socialista na sociedade capitalista será uma terceira coisa, diferente das duas que a geraram, a saber: $\mathrm{O}$ Estado Servil'(HAYEK, 1977, p. 14).

A civilização que fora desenvolvida desde a Renascença desapareceu levando consigo a civilização ocidental e seu individualismo marcante. Emerge, simultaneamente, outro individualismo: 
aquele que a pessoa procura dirigir a própria vida, tendo a oportunidade de escolher e eleger novas formas de existência, sempre ligada ao desenvolvimento do comércio.

A contribuição do século XIX ao individualismo do período precedente foi apenas dar consciência da liberdade a todas as classes, desenvolver sistemática e continuamente o que havia crescido ao acaso e de modo fragmentário, e irradiá-lo da Inglaterra e Holanda para a maior parte do continente europeu (HAYEK, 1977, p. 17).

Ser humano livre e sociedade livre faziam parte dos princípios básicos do liberalismo cuja expansão dependeria da conquista do crescente domínio intelectual sobre as forças sociais e da implementação de um novo sistema monetário eliminando ou pelo menos mantendo o controle sobre o monopólio. Incitar a competição, ampliar a liberdade industrial, melhorar as instituições fundamentais de uma sociedade livre, desenvolver as forças sociais e das condições mais favoráveis ao seu bom funcionamento então entre as principais preocupações do desenvolvimento da sociedade liberal. Todavia, esse "Caminho da Liberdade era de fato a Estrada Real da Servidão" (HAYEK, 1977, p. 26).

O planejamento econômico como gerador de servidão consiste de que ele "pode produzir o oposto daquilo que promete" (HAYEK, 1977, p. 205), pois as autoridades centrais e locais controlam indiretamente o uso de mais de metade da renda nacional; e, é incrível a inoperância e a incapacidade das assembleias democráticas que se soma à ineficácia dos parlamentos. Por isso o totalitarismo se concretiza em variáveis como o sistema fascista ou comunista desde que o controle central esteja a cargo da atividade econômica, uma vez que o "planejamento econômico produz tais resultados indesejáveis" (HAYEK, 1977, p. XXII).

O planejamento econômico, destacado nas análises de Hayek (1977), transformou profundamente tanto o capitalismo quanto as sociedades desenvolvidas sob sua égide. Encontrou, no neoliberalismo, sua nova dinâmica. É dela que tratará as iniciativas de Dardot e Laval (2016, p.7) por compreender que o "capitalismo é indissociável da história de suas metamorfoses, de seus descarrilamentos, das lutas que o transformaram, das estratégias que o renovam". Eles desejam analisar os estragos produzidos pelo neoliberalismo na atual ordem existente.

A resistência ao sistema neoliberal emergirá na medida em que houver produção de conhecimentos sobre sua gênese e seu funcionamento, pois atualmente é dele que emanam todas as ordens e direção seja do ponto de vista político, econômico ou social. O neoliberalismo prossegue produzindo o oposto daquilo que promete e que para Dardot e Laval (2016) se coloca nestes termos:

\footnotetext{
Como é que, apesar das consequências catastróficas a que nos conduziram as políticas neoliberais, essas políticas são cada vez mais ativas, a ponto de afundar os Estados e as sociedades em crises políticas e retrocessos sociais cada vez mais graves? Como é que, há mais de trinta anos, essas mesmas políticas vêm se desenvolvendo e se aprofundando, sem encontrar resistências suficientemente substanciais para colocá-las em xeque? (DARDOT; LAVAL, 2016, p. 15).
}

A busca de outra racionalidade, como propõe esse texto, contribuirá com a produção de outros conhecimentos sobre a gênese e funcionamento do sistema neoliberal em que se desenvolve a luta econômica de uns contra os outros, em que a lógica consiste da pessoa se comportar como uma 
empresa, pois como esclarece Dardot e Laval (2016, p. 17) "a racionalidade neoliberal tem como característica principal a generalização da concorrência como norma de conduta e da empresa como modelo de subjetivação".

Desta concepção faz parte o convencimento de que o governo não é uma instituição, mas uma atividade que, juntamente com as demais, tentarão fazer com que o indivíduo se conforme por si mesmo dentro desse cipoal de normas de conduta e da logica nas relações sociais, já que

[...] os mercados conquistaram a partir de fora os Estados e ditam a política que estes devem seguir, foram antes os Estados, e os mais poderosos em primeiro lugar, que introduziram e universalizaram na economia, na sociedade e até neles próprios a lógica da concorrência e o modelo de empresa (DARDOT; LAVAL, 2016, p. 19).

Dessa lógica perversa está em curso a "desdemocratização, que consiste em esvaziar a democracia de sua substância sem a extinguir formalmente" (DARDOT; LAVAL, 2016, p. 20); a governabilidade neoliberal se impõe num quadro normativo amplo para defender a liberdade e "apoiando-se nas margens de manobra concedidas aos indivíduos, orienta de maneira nova as condutas, as escolhas e as praticas desses indivíduos" (idem, p. 21).

O neoliberalismo não separa a economia do quadro jurídico-institucional, pois a mola propulsora da história permanece o poder do capital, que subordina o Estado e a sociedade para que ambos não se afastem do serviço da acumulação infinita. Para atingi-la é preciso ampliar a austeridade; manipular a força política e fazer dos políticos verdadeiras marionetes nas mãos dos que dominam e controlam o poder do dinheiro. "Essa força secreta impele o Estado a apoderar-se de todos os domínios, aproveitando-se do recolhimento dos indivíduos a seus negócios privados" (DARDOT; LAVAL, 2016, p. 43).

As reflexões de DardoteLaval (2016) consideravam e queriam entender as novas formas políticas que exigiam transformações muito mais amplas do que a simples restauração do capitalismo e do liberalismo tradicional. Há um impulso no sentido de modificar radicalmente o modo de exercício do poder governamental, assim como as referencias doutrinais no contexto de transformação das regras de funcionamento do capitalismo.

Revelam uma subordinação a certo tipo de racionalidade política e social articulada à globalização e à financeirização do capitalismo. Em uma palavra, só há "grande virada" mediante a implantação geral de uma nova lógica normativa, capaz de incorporar e reorientar duradouramente políticas e comportamentos numa nova direção (DARDOT; LAVAL, 2016, p. 190).

A característica marcante da estratégia neoliberal consiste em ser uma estratégia sem estrategista, sem um novo modo de regulação em escala global. Para Dardot e Laval (2016, p. 192) esse objetivo se organizou ao "longo do próprio confronto, se imposto a forças muito diferentes em razão da própria logica do confronto e, a partir desse momento, feito o papel catalizador, oferecendo um ponto de encontro a forças até então relativamente dispersas".

As reflexões de Hayek (1977) contribuíram para ampliar a compreensão sobre a futura política econômica intuindo de que somos dependentes das ideias que criamos, as de Dardot e Laval (2016) 
demonstraram a intervenção do estado neoliberal como de uma nova etapa em que as transformações alteraram o capitalismo e as sociedades, as contribuições de Jardim (2009) procuraram interpretar de que no governo Lula a inclusão social via mercado e via fundos de pensão ocorreram devido à domesticação e moralização do capitalismo.

O governo Lula promove a participação ativa de determinados segmentos sindicais no mercado financeiro (por meio da governança corporativa) e insere preocupações com questões sociais, éticas e com o trabalhador, realizando uma junção entre social e financeiro (JARDIM, 2009, p. 124).

Ela almeja compreender a (res)significação de mecanismos de mercado, como se deu a interação recíproca entre mercado e governo e buscou sentido nas ações e nas opções políticas do governo Lula. Dentro de uma nova organização internacional do capitalismo que é marcado pela fusão e falência de empresas, pela financeirização da produção e por perseguir a rentabilidade a curto prazo, Jardim (2009) ressaltou as características do novo capitalismo. "Neste contexto, atuando no coração do "novo capitalismo" de acumulação financeira, os investidores institucionais são considerados peçaschave da globalização financeira" (JARDIM, 2009, p. 126).

Trata-se de compreender as transformações profundas nas relações e regras sociais, nas modificações das relações de trabalho em meio das quais entender as alterações a partir da "presença de sindicalistas que se têm tornado gestores de fundos de pensão, bem como representantes sindicais nos comitês das empresas, os quais teoricamente passam a decidir o futuro destas" (JARDIM, 2009, p. 127). É o sistema capitalista que procura se adaptar à nova conjectura, diante do qual há transformações em que os de baixo passam a comandar ações que irão interferirnos de cima. Como se os trabalhadores se transformassem em proprietários estabelecendo novo compromisso entre capital e trabalho.

[...] a possível "domesticação e/ou moralização" do governo Lula não é um fenômeno isolado; encontra-se desenvolvido de formas diversas em todo o mundo. Preocupações com investimento ético e responsável, projetos de microcrédito e direitos humanos, entre outros, são retóricas que buscam negar a ideia de "lucro pelo lucro", (res)significando o conceito de mercado financeiro em âmbito internacional (JARDIM, 2009, p. 129).

Para Jardim (2009) é ilustrativa a presença e atuação do presidente Lula em dois eventos nos quais se encontram protagonistas antagônicos ocorridos em 2005: no Fórum Econômico em Davos os patrões representando o capital e no Fórum Social em Porto Alegre os operários representando o trabalho. Eis um exemplo de domesticação e moralização do capitalismo por Lula tentar defender o diálogo entre ambos e procurar criar uma convergência de interesses. "Nos dois encontros, o presidente salientou claramente a necessidade de uma convergência de interesses entre os dois grupos, argumentando sobre a necessidade mútua entre eles" (JARDIM, 2009, p. 131).

Pelos discursos do presidente Lula em ambos os eventos emergem suas iniciativas por intermédio das quais procura abrir caminho para novas iniciativas como, por exemplo, os projetos de inclusão social via parceira público-privada, principalmente no que diz respeito a obras de infraestrutura. "Teve como principal alavancagem os fundos de pensão, ou seja, pretendeu-se contar 
com a poupança dos fundos de pensão para a realização de obras de infraestrutura" (JARDIM, 2009, p. 132).

Na mesma esteira da parceria público-privada a moralização do capitalismo segue com outra iniciativa do governo petista no que tange a microcrédito e do Banco Popular do Brasil. "Naquele momento, o governo priorizou trabalhadores rurais, pessoas de baixa renda, formação de cooperativas e autorizou uma linha de crédito para trabalhadores libertados do regime de escravidão" (JARDIM, 2009, p. 126). Entendeu o governo petista a necessidade de investir nos produtores rurais visando mantê-los no campo.

\section{CONSIDERAÇÕES FINAIS}

As alternativas emancipadoras do Sul Global demonstraram eficiência para construir outra racionalidade apontando possibilidades de se viver e produzir a vida de outra maneira. Essa racionalidade está sendo gerada na periferia do sistema capitalista, dos países subdesenvolvidos, do território dos empobrecidos onde predomina a submissão, o desemprego, a escassez e a fome. Sem as condições mínimas de sobrevivência, pois as mesmas são, cotidianamente, negadas e/ou retiradas, as alternativas de sobrevivência têm emergido pela força da resistência e da solidariedade, já que o amoldamento implica em derrota e aniquilação e, apenas, o enfrentamento criará oportunidades de autonomia e transformação.

As forças da emancipação estão sendo despertadas diante das novas formas de dominação pelas alternativas criadas pelos negros e nações indígenas de toda América Latina; pelos camponeses sem terra organizados pela Via Campesina; assim como, os piqueteiros argentinos, os cocaleiros na Bolívia e no Peru. As estratégias zapatistas no México e os universitários brasileiros que ocuparam as universidades com a luta pela melhoria de ensino. A luta e a rebeldia do precariado que se insurge contra a acumulação por espoliação que impõe um regime com rigorosos planos de austeridade.

A busca de outra racionalidade demonstra a premência em compreender que o neoliberalismo prossegue gerando o oposto daquilo que promete, constituindo-se em gerador de servidão, ao incitar a competição em todas as áreas e direções; ampliar a liberdade industrial; melhorar as instituições fundamentais de uma sociedade livre; desenvolver as forças sociais. É o sistema capitalista com suas artimanhas e adaptações tendo sempre no horizonte seu interesse na acumulação infinita.

\section{REFERÊNCIAS}

1. AMIN, Samir. O desenvolvimento desigual: ensaios sobre as formações sociais do capitalismo periférico. Rio de Janeiro: Forense Universitária, 1976.

2. AMIN, Samir. Geopolítica do imperialismo contemporâneo. Revista Novos Rumos, ano 21, n. 45, p. 3-30, 2006. 
3. ARRIGHI, Giovanni. O Longo Século XX: Dinheiro, poder e as origens de nosso tempo. $7^{\mathrm{a}}$ reimp. Rio de Janeiro: Contraponto, 2009.

4. BRAGA, Ruy. A rebeldia do precariado: trabalho e neoliberalismo no Sul Global. São Paulo: Boitempo, 2017

5. DARDOT, Pierre; LAVAL, Christian. A nova razão do mundo: ensaio sobre a sociedade neoliberal. Tradução: Mariana Echalar. São Paulo: Boitempo, 2016.

6. FLECK, Ludwik. Gênese e desenvolvimento de um fato científico. Belo Horizonte: Fabrefactum, 2010.

7. HAYEK, Friedrich A. von. O caminho da servidão. 2a ed. São Paulo: Globo, 1977.

8. JARDIM, Maria Aparecida C. "Domesticação" e/ou "Moralização do Capitalismo" no Governo Lula: Inclusão Social Via Mercado e Via Fundos de Pensão.In: Revista de Ciências Sociais, Rio de Janeiro. Vol 52, n 1, 2009, pp 123 a 159.

9. KUHN, Thomas S. A Estrutura das Revoluções Científicas. São Paulo: Perspectiva, 2009.

10. MORIN, Edgar. Ciência com Consciência. $13^{a}$ ed. revista e ampliada. Rio de Janeiro: Bertrand Brasil, 2010.

11. POLANYI, Karl. A Grande Transformação. As origens da nossa época. $2^{a}$ ed. $14^{\mathrm{a}}$ reimp. Rio de Janeiro: Elsevier, 2000.

12. ZIBECHI, Raul. La emancipación como producción de vínculos. In: Los desafíos de lasemancipacionesenun contexto militarizado. CECEÑA, Ana Esther. CLACSO, ConsejoLatinoamericano de CienciasSociales, Ciudad Autónoma de Buenos Aires, Argentina, 2006. p. 123-149.

Munir Jorge Felício

Pesquisador credenciado na Catedra UNESCO de Educação do Campo e pesquisador do Núcleo de Estudos, Pesquisas e Projetos de Reforma Agrária - NERA - UNESP, campus Presidente Prudente (SP). Brasil.

\section{Paulo Roberto Rosa}


Doutorando em Geografia da Universidade Estadual Paulista "Júlio de Mesquita Filho" (UNESP), Faculdade de Ciências e Tecnologia, Presidente Prudente/SP; Docente no Instituto Federal de Educação, Ciência e Tecnologia de São Paulo (IFSP) - campus de Presidente Epitácio; Integrante do Núcleo de Estudos, Pesquisas e Projetos de Reforma Agrária (NERA).

\section{Como citar este documento:}

FELÍCIO, Munir Jorge; ROSA, Paulo Roberto. EM BUSCA DE OUTRA RACIONALIDADE. Reflexão e Ação, Santa Cruz do Sul, v. 29, n. 1, p. 233-247, jan. 2021. ISSN 1982-9949. Acesso em: doi: http://dx.doi.org/10.17058/rea.v29i1.13785 